\title{
"I WATCH YOU": UMA ANÁLISE DIALÓGICA DA LINGUAGEM VERBO-VISUAL DE CAPA DA REVISTA ÉPOCA SOBRE A ESPIONAGEM DIGITAL DO GOVERNO NORTE-AMERICANO
}

\author{
ELAYNE GONÇALVES SILVA ${ }^{1}$ \\ JOÃO BATISTA COSTA GONÇALVES ${ }^{2}$
}

\author{
Programa de Pós-Graduação em Linguística Aplicada (PosLA) \\ Universidade Estadual do Ceará \\ Av. Luciano Carneiro, 345 - 60410-690 - Fortaleza - CE - Brasil \\ elaynegsilva@gmail.com ; jbcgoneig.com.br
}

\begin{abstract}
Resumo. No trabalho, buscou-se analisar, com base na abordagem dialógica do Círculo de Bakhtin, a linguagem verbo-visual da capa da edição $n^{\circ} 790$ da revista Época, que se caracterizou por construir sentidos relativos à vigilância digital realizada pelos Estados Unidos. Este texto marcou-se por aproximar o presidente norte-americano Barack Obama da famosa imagem da personagem Tio Sam e por fazer uma crítica ao sistema de espionagem digital desenvolvido pela inteligência norte-americana. A partir do estudo, foi possível concluir que, nessa capa, a revista Época inscreveu-se ideologicamente em relação ao assunto abordado e que o material analisado foi construído dialogicamente, estabelecendo relações de sentido com o discurso da propaganda de guerra dos Estados Unidos.
\end{abstract}

Palavras-chave: linguagem verbo-visual; signo ideológico verbo-visual; dialogismo; relações dialógicas; Época.

\begin{abstract}
In this paper, we aimed to analyze, based on the dialogic approach of the Bakhtin Circle, the verb-visual language of the cover of the edition number 790 of Época magazine, which characterized by constructing meanings related to the digital surveillance performed by the United States. This text was marked by approaching the North American president Barack Obama to the famous image of the character Uncle Sam and by making a criticism on the system of digital spy developed by the U.S. intelligence. With the study, it was possible to conclude that, in this cover, Época magazine inscribed itself ideologically in relation to the issue addressed and that the analyzed material was constructed dialogically, establishing meaning relations with the discourse of the war propaganda from the U.S.
\end{abstract}

Keywords: verb-visual language; verb-visual ideological sign; dialogism; dialogical relations; Época.

\footnotetext{
${ }^{1}$ Mestranda em Linguística Aplicada pelo Programa de Pós-Graduação em Linguística Aplicada (PosLA) da Universidade Estadual do Ceará (UECE).

${ }^{2}$ Doutor em Linguística (UFC). Docente na Graduação e no Programa de Pós-Graduação em Linguística Aplicada (PosLA) da Universidade Estadual do Ceará (UECE).
} 


\section{Introdução}

Tomando a perspectiva da Análise Dialógica do Discurso ${ }^{3}$, é pertinente afirmar que o discurso midiático se caracteriza por ser revestido de elementos ideológicos e, portanto, axiológicos ${ }^{4}$. Sobre essa questão, Stam (2010, p. 333) concebe que, para uma abordagem bakhtiniana, "a mídia de massa pode ser conceituada como uma 'rede complexa de signos ideológicos"”. Com apoio nas observações de Stam (2010, p. 333), podemos dizer que o discurso da mídia de massa constitui, portanto, um espaço de veiculação e de materialização de ideologias, ainda que a própria esfera midiática recorrentemente se refira à neutralidade, à imparcialidade e o compromisso com "a verdade dos fatos" que, supostamente, caracterizariam seu fazer discursivo.

A esse respeito, torna-se pertinente esclarecer qual o conceito de discurso que utilizamos nesse estudo. Na obra Problemas da poética de Dostoievski, Bakhtin (2010, p. 207) define o termo como

a língua em sua integridade concreta e viva, e não a língua como objeto específico da linguística, obtido por meio de uma abstração absolutamente legítima e necessária de alguns aspectos da vida concreta do discurso. (BAKHTIN, 2010, p. 207)

Desse modo, segundo a perspectiva bakhtiniana, o discurso é concebido como linguagem em uso concreto e não se encontra despido de aspectos valorativos, em função de ser construído através de um constante diálogo com o discurso de outrem.

A capa ${ }^{5}$ da edição $n^{\circ} 790$ da revista Época, objeto de análise do presente trabalho, corresponde a um exemplo de material multissemiótico em que tendências ideológicas se presentificam na linguagem, materializando-se em signos ideológicos verbais e visuais. Nesse texto, por meio das relações que se estabelecem entre os planos semióticos verbal e imagético, a referida publicação constrói, dialogicamente, a imagem do então presidente norte-americano, Barack Obama, assim como constrói sua interpretação e se posiciona avaliativamente em relação à vigilância eletrônica realizada pela agência de inteligência estadunidense, processo esse que se deu mediante a utilização de um sistema de espionagem digital.

Conforme amplamente divulgado pela mídia, os detalhes sobre o processo de espionagem eletrônica realizado pela inteligência norte-americana foram revelados ao

\footnotetext{
${ }^{3}$ Termo empregado por Brait (2010a) para designar a proposta de estudo da linguagem do Círculo de Bakhtin. Brait (2010a) defende que o conjunto de obras dos pensadores motivou o nascimento de uma análise ou de uma teoria dialógica do discurso, "ainda que [os integrantes do Círculo] jamais tenham postulado um conjunto de preceitos sistematicamente organizados para funcionar como perspectiva teóricoanalítica fechada" (BRAIT, 2010a, p. 9-10).

${ }^{4}$ Isso porque, como explica Faraco (2009, p. 46), em determinadas passagens de obras do Círculo bakhtiniano, "[...] o adjetivo ideológico aparece como equivalente a axiológico" (grifos do autor). Desse modo, as duas expressões, na perspectiva bakhtiniana, estabelecem uma relação de sinonímia entre si.

${ }^{5}$ No gênero discursivo capa de revista, são apresentadas, de maneira sintetizada, as principais matérias componentes de determinada edição. Esse texto costuma ser constituído pela associação entre diferentes planos semióticos, razão pela qual o denominamos "multissemiótico". Este é o caso da capa de revista que buscaremos analisar.
} 
jornal britânico The Guardian por Edward Snowden, técnico e ex-consultor da Agência de Segurança Nacional (NSA). Snowden divulgou inúmeros documentos sigilosos dos Estados Unidos, além de ter denunciado um amplo esquema de monitoramento de conversas e de troca de mensagens entre os cidadãos norte-americanos. De acordo com fontes da Agência de Segurança Nacional (NSA), o processo de vigilância digital deu-se através do PRISM, que é "uma iniciativa do governo norte-americano para monitoramento da internet como um todo" (AGUILHAR, 2013). Esse programa foi desenvolvido com o objetivo inicial de armazenar mensagens de indivíduos suspeitos de terem ligações com o terrorismo. Contudo, uma falha no programa em questão teria possibilitado acesso às informações digitais e ao e-mail de cidadãos comuns.

O processo de espionagem digital realizado pela inteligência norte-americana foi um dos assuntos abordados na capa da edição 790 da Época. De acordo com a teoria bakhtiniana, todo discurso é ideológico, como assevera Ponzio (2012, p. 116). Logo, o discurso midiático apresenta, inevitavelmente, uma dimensão ideológico-valorativa. Por esse motivo, podemos afirmar que as publicações costumam inscrever-se ideologicamente nas capas de suas edições e em suas reportagens, expressando seu ponto de vista e tomando posicionamentos axiológicos em relação aos temas que abordam, como é o caso do material em foco.

Para realizar nosso estudo, basear-nos-emos nas propostas do Círculo de Bakhtin, como antecipamos. Nas palavras de Brait (2013, p. 44), "os estudos de Bakhtin e do Círculo constituem contribuições para uma teoria da linguagem em geral e não somente para uma teoria da linguagem verbal, quer oral ou escrita" (grifos da autora). Assim, apesar de a perspectiva bakhtiniana apresentar uma preocupação com as diferentes semioses que interagem na construção dos sentidos de discursos e de enunciados, seu potencial para o estudo de materiais textuais e discursivos de natureza multissemiótica ainda não foi devidamente explorado. Dessa maneira, uma investigação a respeito de como os signos ideológicos verbais e visuais associam-se para produzir sentidos no gênero discursivo capa de revista contribuiria para dar continuidade às reflexões sobre a verbo-visualidade à luz da análise dialógica do discurso.

O trabalho tem, portanto, o objetivo de analisar, a partir da abordagem bakhtiniana, como os signos ideológicos, nos planos semióticos verbal e visual, estabelecem relações dialógicas na capa da revista Época. Intentaremos observar como os materiais sígnicos verbais e visuais da referida capa se relacionam uns com os outros e expressam o ponto de vista da publicação no que se refere à espionagem digital estadunidense, manifestando a orientação ideológica de Época sobre o assunto.

No que se refere à organização, o artigo, além desta seção introdutória, será composto por outras três seções. Na segunda seção, faremos considerações sobre os conceitos de dialogismo, de relações dialógicas e de signo ideológico, nos quais a análise da capa da revista basear-se-á; na terceira, realizaremos a análise do referido texto a partir dos conceitos discutidos e, finalmente, na quarta seção, apresentaremos uma síntese do assunto estudado, bem como nossas considerações finais acerca da linguagem verbovisual da capa da edição no 790 da revista Época. 


\section{Exposição das noções e das categorias de análise}

\subsection{Dialogismo/Relações dialógicas}

Para realizarmos a análise dialógica da referida capa, basear-nos-emos, conforme antecipamos, nos conceitos de dialogismo/relações dialógicas e de signo ideológico, além das propriedades do material sígnico de refletir e de refratar a realidade social. Torna-se importante afirmar que, no trabalho, buscaremos estudar as relações dialógicas, isto é, a maneira como o dialogismo, efetivamente, se manifesta em materiais textuais e/ou discursivos. A esse respeito, Bakhtin (2010, p. 211) destaca que, quando entendidas em sentido amplo, as relações dialógicas não estão restritas à dimensão verbal da linguagem: "estas são possíveis também entre outros fenômenos conscientizados, desde que estejam expressos numa matéria sígnica" (grifo do autor). Considerando esse fragmento textual, é possível asseverar que as relações dialógicas podem presentificar-se em materiais compostos por signos verbais e/ou visuais, como é o caso da capa de revista que nos propusemos a analisar.

Antes de pensarmos mais detidamente sobre o dialogismo e sobre as relações dialógicas, torna-se fundamental refletir sobre a noção de enunciado, um dos objetos de estudo da Translinguística ${ }^{6}$ proposta por Bakhtin. Sobre esse assunto, Fiorin (2006, p. 2223), interpretando o pensamento bakhtiniano, destaca que os enunciados apresentam uma dimensão autoral ${ }^{7}$, revelam a tomada de determinada posição axiológica por parte do enunciador, exigem uma resposta do enunciatário e carregam juízos de valor, não sendo, portanto, ideologicamente neutros.

Além disso, segundo Bakhtin (2011, p. 299), "Cada enunciado isolado é um elo na cadeia da comunicação discursiva". O autor defende que um enunciado, portanto, se orienta tanto para enunciados que já foram produzidos - elos precedentes - quanto para enunciados que ainda serão produzidos - elos subsequentes da cadeia da comunicação discursiva. Acosta-Pereira e Rodrigues (2010, p. 149), com base nas ideias do Círculo bakhtiniano, propõem os termos "enunciados já-ditos" e "enunciados pré-figurados" para designar, respectivamente, os enunciados predecessores e os enunciados sucessores dessa corrente de interação discursiva para os quais todos os enunciados são duplamente orientados. Ainda no que se liga a essa dupla orientação dos enunciados, os autores citados concebem que:

Ao mesmo tempo que os enunciados, do ponto de vista da eventicidade, são únicos e irrepetíveis, do ponto de vista da historicidade, eles são dialógicos, pois, como unidades concretas da comunicação, dialogam constantemente na concretude das interações com outros enunciados

\footnotetext{
6 Os intérpretes contemporâneos do pensamento do Círculo de Bakhtin empregam os termos "Translinguística" ou "Metalinguística" para designar a ciência de estudo da linguagem proposta pelo grupo, a qual teria como objeto de estudo as relações dialógicas, como explica Bakhtin (2010, p. 208). Caberia, assim, à Translinguística (ou à Metalinguística) estudar os enunciados e as relações de sentido que se estabelecem entre eles, ou seja, as relações dialógicas.

${ }^{7}$ Consoante Bakhtin (2010, p. 210), o autor pode ser compreendido como o "criador de dado enunciado cuja posição ele expressa". Logo, uma das marcas características de um enunciado é a manifestação do ponto de vista e de uma posição axiológica de seu autor, o que reitera a tese bakhtiniana de que "um enunciado absolutamente neutro é impossível” (BAKHTIN, 2011, p. 289).
} 
(já-ditos e pré-figurados), "tecendo" sentidos. (ACOSTA-PEREIRA; RODRIGUES, 2010, p. 150)

Tendo discutido o conceito bakhtiniano de enunciado, pensemos, a partir de agora, na questão do dialogismo. De acordo com a perspectiva do Círculo de Bakhtin, na construção de um determinado discurso, um enunciador sempre recuperará discursos anteriormente construídos e sempre provocará o surgimento de novos discursos. Bakhtin (2014, p. 88) afirma que "Em todos os seus caminhos até o objeto, em todas as direções, o discurso se encontra com o discurso de outrem e não pode deixar de participar, com ele, de uma interação viva e tensa". Ou seja, para essa postura teórica, todo discurso produzido será orientado dialogicamente para uma multiplicidade de discursos de outrem e gerará, por seu turno, novos discursos. É nesse sentido que podemos dizer que os discursos se encontram sempre num constante diálogo uns com os outros, respondendo discursos anteriormente produzidos e, também, provocando o surgimento de novas respostas, na forma de discursos que ainda serão produzidos. Tais respostas, por sua vez, são acompanhadas por tomadas de posições pelos participantes dessa relação interdiscursiva ininterrupta.

Ademais, torna-se pertinente observar a ligação entre os discursos e as relações dialógicas. De acordo com Bakhtin (2010, p. 209), "essas relações se situam no campo do discurso, pois este é por natureza dialógico [...]", uma vez que todo discurso se constitui com relação a outros discursos. Para o Círculo de Bakhtin, portanto, o discurso é constitutivamente dialógico, funcionando como uma resposta a discursos anteriores e, simultaneamente, exigindo novas respostas.

Ainda a respeito do dialogismo, Fiorin (2010, p. 167) reflete sobre a questão do acesso dos sujeitos à realidade, que não se dá de maneira direta, sendo, ao contrário, mediado por signos. Nas palavras do próprio autor,

o real se apresenta para nós semioticamente, o que implica que nosso discurso não se relaciona diretamente com as coisas, mas com outros discursos que semiotizam o mundo. Essa relação entre os discursos é o dialogismo. (FIORIN, 2010, p. 167)

Desse modo, tomando o excerto supracitado, podemos concluir que o dialogismo corresponde às relações de sentido que se estabelecem entre discursos e entre enunciados. Pensando sobre o papel da linguagem como mediadora do acesso dos indivíduos à realidade social e na semiotização dos objetos do mundo, Faraco (2009) atenta para o caráter valorativo do enunciado. Segundo o autor, "como a significação dos signos envolve sempre uma dimensão axiológica, nossa relação com o mundo é sempre atravessada de valores" (FARACO, 2009, p. 49). O fenômeno da significação, portanto, de acordo com a perspectiva dialógica, mostra-se inseparável de um processo de atribuição de valores aos objetos de nossos dizeres, de modo que não seria possível significar sem valorar. As palavras de Bakhtin/Volochínov (1976) no texto Discurso na vida e discurso na arte: sobre poética sociológica ${ }^{8}$ são bastante esclarecedoras a esse

\footnotetext{
${ }^{8}$ Sabe-se, atualmente, que referido o texto, que faz parte da obra Freudismo, é de autoria de Volochínov. No entanto, como a tradução feita por Carlos Alberto Faraco e por Cristovão Tezza, utilizada por nós na elaboração do trabalho, dá créditos a Bakhtin e a Volochínov pela autoria de Discurso na vida e discurso na arte, decidimos, em respeito ao material consultado, considerar o nome de ambos os autores em nosso artigo.
} 
respeito. De acordo com os pensadores, "Todos os fenômenos que nos cercam estão do mesmo modo fundidos com julgamentos de valor" (BAKHTIN/VOLOCHÍNOV, 1976, p. 6).

Dessa forma, podemos perceber que a significação encontra-se ligada a uma apreciação feita pelo enunciador sobre determinado objeto ou evento do mundo. Ponzio (2012, p. 115), pautado no pensamento bakhtiniano, explica que "no signo ideológico, está sempre presente uma 'acentuação valorativa', que faz com que o mesmo não seja simplesmente a expressão de uma 'ideia', mas a tomada de posição determinada, [...]." Dito de outro modo, os sujeitos do discurso, ao darem sentido ao mundo, dão-lhe, simultaneamente, valorações sociais.

\subsection{Signo ideológico}

No estudo que desenvolve sobre a noção de ideologia na visão do Círculo de Bakhtin, Ponzio (2012, p. 113) destaca que, diferentemente de como é compreendido na visão marxista, o termo "ideologia", na perspectiva dialógica, não corresponde totalmente às ideias de "falsa consciência" e de "pensamento distorcido". Para que compreendamos como esse conceito é pensado pelo Círculo de Bakhtin, consideramos interessante observar a definição de ideologia dada por Volochínov (1930 apud PONZIO, 2012, p. 114):

Por ideologia entendemos todo o conjunto dos reflexos e das interpretações da realidade social e natural que tem lugar no cérebro do homem e se expressa por meio de palavras [...] ou outras formas sígnicas. (VOLOCHÍNOV, 1930 apud PONZIO, 2012, p. 114)

Tomando o excerto acima, podemos afirmar que uma reflexão sobre a ideologia, se realizada a partir de uma perspectiva bakhtiniana, consiste, necessariamente, em uma reflexão sobre a linguagem (entendida aqui em sentido amplo, abrangendo tanto sua modalidade verbal quanto sua modalidade visual). Isso porque, como explicam Bakhtin/Volochínov (2012, p. 31), "tudo que é ideológico possui um significado e remete a algo situado fora de si mesmo. Em outros termos, tudo que é ideológico é um signo. Sem signos não existe ideologia" (grifos dos autores). Para Bakhtin/Volochínov (2012, p. 31), portanto, não seria possível pensar a ideologia sem que ela esteja materializada semioticamente, ou seja, sem que ela esteja ganhe existência material no terreno da linguagem.

Além disso, Bakhtin/Volochínov (2012, p. 31) compreendem a significação como um fenômeno que envolve duas operações sígnicas distintas, porém inseparáveis e de ocorrência simultânea: a reflexão e a refração. Consoante Bakhtin/Volochínov (2012, p. 31), "Um signo não existe apenas como parte de uma realidade; ele também reflete e refrata uma outra. Ele pode distorcer essa realidade, ser-lhe fiel ou apreendê-la de um ponto de vista específico etc".

A reflexão sígnica pode ser compreendida como a descrição do mundo que fazemos com signos. Levando em consideração o caráter avaliativo do signo ideológico, podemos dizer, apoiando-nos em Miotello (2012, p. 170), que os sujeitos do discurso se utilizam de materiais sígnicos com os quais descrevem e interpretam a realidade partir de 
um lugar valorativo; ou seja, os signos manifestam pontos de vista e posicionamentos axiológicos dos enunciadores.

Para que compreendamos melhor a refração sígnica, consideramos pertinente recorrer à explanação feita por Faraco (2009). Segundo esse autor, diferentes grupos humanos passam por experiências concretas caracterizadas pela multiplicidade e pela heterogeneidade; dessas experiências, decorrem as variadas interpretações que tais grupos fazem a respeito do mundo. Devido ao caráter múltiplo e heterogêneo de suas vivências, diferentes classes sociais que compartilham de uma língua saturam um mesmo signo com índices de valor distintos, os quais podem, inclusive, estabelecer relações de contraditoriedade entre si. Consoante Faraco (2009, p. 50), "a práxis dos grupos humanos vai gerando diferentes modos de dar sentido ao mundo (de refratá-lo), que vão se materializando e se entrecruzando no mesmo material semiótico" (grifo do autor). Nesse sentido, a refração pode ser compreendida como as diferentes formas por meio das quais as classes sociais interpretam e dão sentido ao mundo.

Ainda sobre o assunto, Faraco (2009, p. 55) nota que Bakhtin, por sua vez, caracteriza a refração "como a atmosfera multidiscursiva que recobre qualquer objeto (tomado este termo aqui em sentido amplo) da realidade, dando-lhe múltiplos nomes, definições e julgamentos de valores". Não encontramos nenhum objeto do mundo despido de um conjunto de nomes e de valorações sociais previamente construídos a respeito dele no âmbito do discurso de outrem. Assim, também podemos compreender a refração como essa densa camada social de discursos que recobre todo e qualquer objeto da realidade, para a qual nossas palavras se voltam, já que, consoante Faraco (2009, p. 49), "nossas palavras não tocam as coisas, mas penetram na camada de discursos sociais que recobrem as coisas".

\section{3. "I watch you": análise dialógica dos signos ideológicos verbo-visuais em uma capa da revista Época}

Conforme mencionamos, a capa da edição ${ }^{\circ} 790$ da revista Época foi selecionada como objeto de análise de nosso trabalho. Esse material marca-se por apresentar uma dimensão dialógica e por representar, de maneira nitidamente negativa, Barack Obama e o sistema de espionagem digital dos Estados Unidos. Materiais semióticos - e, por consequência, ideológicos - de natureza verbal e visual foram utilizados para dar sentido à vigilância eletrônica realizada pela inteligência norte-americana e ao papel desempenhado pelo referido presidente estadunidense nessa questão.

Para realizar nossa análise, procederemos da seguinte maneira: inicialmente, apresentaremos uma descrição mais geral tanto dos aspectos verbais quanto dos aspectos visuais que compõem a capa em estudo; em seguida, deter-nos-emos nos signos ideológicos visuais; posteriormente, faremos considerações acerca dos signos ideológicos verbais e, por fim, observaremos as relações que se estabelecem entre esses dois meios semióticos. Considerando esses aspectos, analisaremos de que maneira, com a utilização da linguagem em suas modalidades verbal e visual, Época, ao recuperar um enunciado "já-dito" no contexto da Primeira Guerra Mundial, expressa, semioticamente, seu ponto de vista e seu juízo de valor sobre a questão da espionagem digital norte-americana, assim 
como constrói dialogicamente a imagem de Barack Obama e o contexto da vigilância eletrônica.

Abaixo, na Figura 1, reproduzimos a capa da edição 790 da Época.

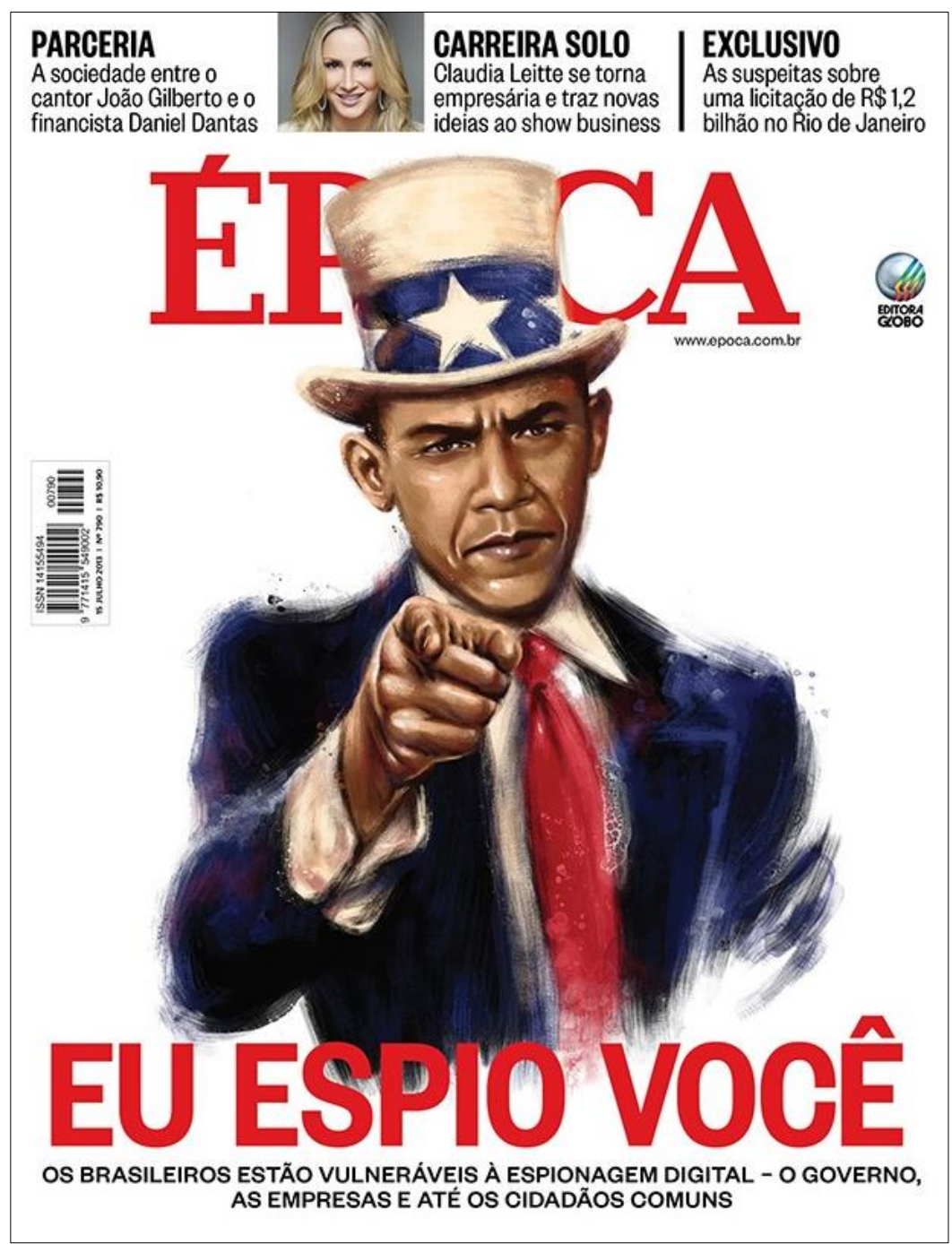

Figura 1. Capa da edição 790 da revista Época.

Inicialmente, façamos uma descrição global desse texto. A capa da edição 790 da Época é composta, visualmente, por uma imagem caricatural do presidente Barack Obama. A figura do presidente estadunidense ocupa a parte central da capa e está acompanhada pelas construções "Eu espio você" e "Os brasileiros estão vulneráveis à espionagem digital - o governo, as empresas e até os cidadãos comuns". Atrás da caricatura do então presidente dos Estados Unidos, encontra-se o nome da revista Época, abaixo do qual estão um símbolo da Editora Globo e o endereço eletrônico da publicação (www.epoca.com.br). É importante apontar também que, acima da representação imagética de Obama, são apresentadas informações relativas a outras matérias presentes naquela edição (A parceria entre João Gilberto e Daniel Dantas, a carreira de Cláudia Leite e uma licitação de $\mathrm{R}$ \$ 1,2 bilhão no estado do Rio de Janeiro). Em nosso trabalho, 
no entanto, não nos deteremos nesses outros aspectos da capa da revista, concentrandonos na questão da vigilância eletrônica.

Pensemos, agora, na dimensão imagética desse texto. No centro da capa, podemos observar um signo ideológico imagético, que corresponde à figura masculina vestida com um fraque, no caso, uma vestimenta composta por uma sobrecasaca de cor azul escura, sobre uma camisa de cor branca e uma gravata vermelha. $\mathrm{O}$ traje formal é acompanhado por uma cartola branca, que apresenta uma faixa na tonalidade azul escura, com estrelas brancas. Essa figura está com o dedo em riste e apresenta uma expressão facial severa, com os cantos da boca levemente voltados para baixo e com um olhar inflexível, que, assim como seu dedo indicador, parece se dirigir diretamente para o leitor da revista. $\mathrm{O}$ rosto da ilustração corresponde ao do então presidente dos Estados Unidos, Barack Obama. O nome do autor dessa ilustração não é explicitado; quem a assina é a própria revista Época, que tem o nome expresso atrás da figura de Obama.

No que concerne aos elementos verbais, logo abaixo da figura masculina, na parte inferior da capa, temos o enunciado "Eu espio você", em caixa alta, numa fonte de tamanho grande e na cor vermelha. Abaixo desse enunciado, encontramos outro, que objetiva esclarecer o primeiro: “Os brasileiros estão vulneráveis à espionagem digital - o governo, as empresas e até os cidadãos comuns”. Este segundo enunciado também está grafado em caixa alta, mas, diferentemente do primeiro, é apresentado numa fonte de tamanho menor e na cor preta.

Ao escolher representar Obama com o fraque e a cartola, vestimentas semelhantes àquelas utilizados por Tio Sam, a Época pode conduzir o leitor a associar o então presidente norte-americano à famosa personagem que figura nos cartazes de recrutamento para o exército dos Estados Unidos, datados do período da Primeira Guerra Mundial. Nesse sentido, faz-se relevante observar as considerações que Bakhtin/Volochínov (2012, p. 31) fazem a respeito da conversão de um corpo físico em um signo:

todo corpo físico pode ser percebido como um símbolo. [...] toda imagem artístico-simbólica ocasionada por um objeto físico particular já é um produto ideológico. Converte-se, assim, em signo o objeto físico, o qual, sem deixar de fazer parte da realidade material, passa a refletir e a refratar, numa certa medida, uma outra realidade. (BAKHTIN/VOLOCHÍNOV, 2012, p. 31)

Podemos verificar, nesse material multissemiótico, a transformação de um corpo físico, no caso, o do presidente norte-americano, em um signo ideológico visual. Ao recuperar a personagem Tio Sam para aproximá-la de Obama e ao resgatar o contexto da Primeira Guerra Mundial para aproximá-la da espionagem digital, a Época "prolonga" as características da personagem e do evento bélico para o então presidente norte-americano e para a vigilância eletrônica. É como se Obama assumisse a posição de autoridade que pertencia a Tio Sam: enquanto este representava a liderança na Primeira Guerra, aquele materializa a liderança na guerra virtual contemporânea.

$\mathrm{Na}$ propaganda bélica norte-americana, a personagem Tio Sam (Figura 2) corresponde a um símbolo da liderança nacional, uma figura representativa da necessidade de defender o território dos Estados Unidos, combatendo as nações inimigas. 
Dessa maneira, a escolha de relacionar Obama ao Tio Sam mostra-se, inevitavelmente, ideológica: Obama, bem como Tio Sam, é concebido também como um líder, e ambos estão inseridos em conflitos, ainda que cada um desses conflitos tenha características particulares. Dessa forma, para a Época, enquanto Tio Sam está envolvido num conflito bélico real, Obama está inserido em uma guerra eletrônica, que se dá através do sistema de espionagem digital. Na reportagem completa sobre o assunto, a Época, inclusive, afirma que os computadores e a internet são armas utilizadas pelo serviço de inteligência dos Estados Unidos; os alvos dessa guerra virtual, bem como da vigilância eletrônica estadunidense, no lugar de outros países, conforme acontecia em conflitos bélicos reais, como é o caso da Primeira Guerra Mundial, seriam, na atualidade, "o governo, as empresas e até os cidadãos comuns", como a publicação enumera no segundo enunciado verbal a que fizemos menção.

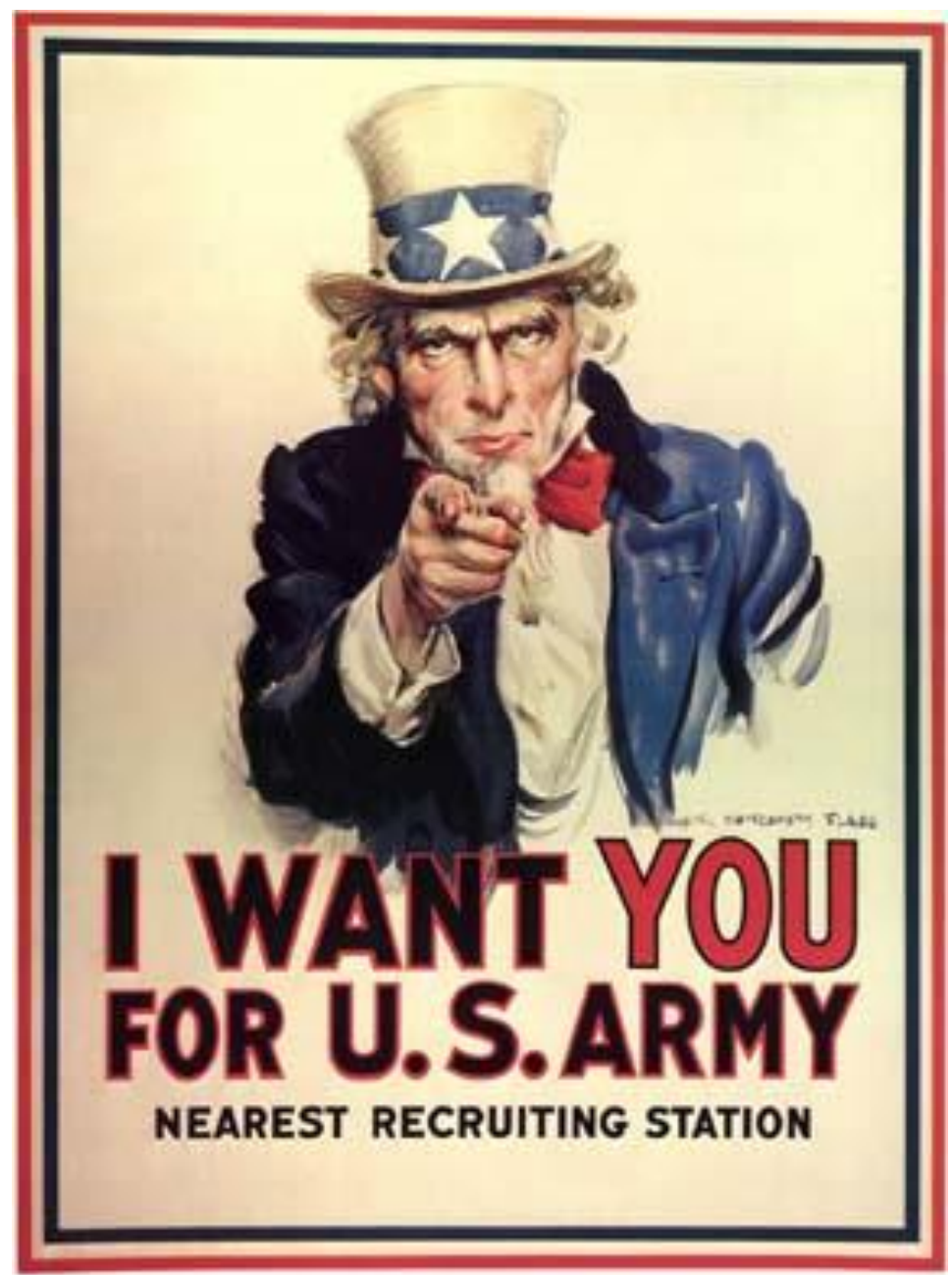

Figura 2. Cartaz de recrutamento dos jovens militares para o exército dos Estados Unidos, ilustrado por James Montgomery Flagg e utilizado durante a Primeira Guerra Mundial.

Consideramos interessante, nesse ponto do trabalho, fazer uma breve interrupção de nossa explanação para descrever, de modo sucinto, os aspectos verbais e visuais do pôster em foco. Assim, a figura apresentada acima corresponde ao cartaz ilustrado por 
James Montgomery Flagg, no contexto da Primeira Guerra Mundial; cartaz este que é recuperado dialogicamente pela Época para representar discursivamente Obama e a vigilância digital norte-americana na capa da edição 790 .

No cartaz de Flagg, no que tange à dimensão visual, temos uma personagem masculina, Tio Sam, que ocupa uma posição central no pôster, vestindo um fraque, com uma sobrecasaca azul, sobreposta a uma camisa branca e a uma gravata borboleta vermelha. A personagem usa uma cartola branca, que apresenta uma faixa de cor azul, na qual se encontram estrelas brancas. Ademais, Tio Sam aponta para o leitor de sua mensagem, que é convocado a se juntar ao exército estadunidense, devendo, para tanto, dirigir-se à estação de recrutamento mais próxima.

Já no que se refere à dimensão verbal, temos os dizeres "I want you" ("For U.S. Army nearest recruiting station"). ("Eu quero você/ na estação mais próxima de recrutamento do Exército dos Estados Unidos"). Interessante notar ainda que "I want you for U.S. Army" é grafado em caixa alta, numa fonte de tamanho grande e na cor preta, com exceção do termo "you", que apresenta cor vermelha. Já a expressão adverbial de lugar "nearest recruiting station" é grafada numa fonte de tamanho menor, em caixa alta e na cor preta, funcionando como uma espécie de "subtítulo" explicativo para "I want you for U.S. Army", uma vez que esclarece o sentido do verbo "querer". Logo acima desses dizeres, podemos ver, ainda que com pouca nitidez, a assinatura de James Montgomery Flagg, indicativa da autoria da ilustração.

Tendo descrito o pôster de Flagg, voltemos a pensar sobre as relações de sentido existentes entre ele e a capa da Época. Dentre diferentes ícones culturais com os quais a publicação poderia relacionar a figura de Obama e o sistema de espionagem digital do serviço de inteligência norte-americano, a Época optou por recuperar a figura do Tio $\mathrm{Sam}^{9}$, retomada essa que se dá, no plano visual, pelo fato de que, na capa em estudo, a imagem que representa Obama possui as mesmas vestimentas e uma postura similar às da personagem Tio Sam e, no plano verbal, através de enunciado "Eu espio você", que foi constituído com base na convocação característica do cartaz de Flagg, "I want you" (For U.S. Army nearest recruiting station") ("Eu quero você/ na estação mais próxima de recrutamento do Exército dos Estados Unidos").

Quando resgata a personagem Tio Sam para construir a imagem de Obama, a revista Época se posiciona avaliativamente em relação à espionagem digital norteamericana: trata-a em termos de uma guerra digital e, inclusive, faz referência à condição de vulnerabilidade à qual estão sujeitos o governo, as empresas e os cidadãos comuns espionados, que podem não ter conhecimento de que estão sendo vigiados pelos Estados Unidos. Dessa maneira, a revista confere um sentido negativo tanto a esse processo quanto a Obama, que pode ser interpretado como líder e, sobretudo, como um espião estadunidense. Reiteramos, assim, a ideia de que a publicação relaciona a vigilância

\footnotetext{
${ }^{9}$ Sobre a origem da personagem Tio Sam, Silva (2006, p. 122) assinala que é possível que essa figura simbólica remeta ao comerciante Samuel Wilson, um provedor do Exército dos Estados Unidos, que enviava caixotes e fardos para os quartéis norte-americanos. Nesses itens, constava a sigla "U.S. Army" ("Exército dos Estados Unidos"). Os militares norte-americanos faziam uma brincadeira com o primeiro nome do provedor desses itens, Samuel (Sam), e com as iniciais do nome do país, United $\underline{\text { States of }}$ America, conforme assevera Silva (2006, p. 122). A partir desse jogo linguístico feito com as siglas, originou-se a expressão "Uncle Sam Army" ("Exército do Tio Sam"), no lugar de "U.S. Army" ("Exército dos Estados Unidos").
} 
eletrônica a um contexto de guerra, ainda que diferente da Guerra que figurou no cartaz de Flagg. ${ }^{10}$

No que concerne aos aspectos verbais, na capa da Época, temos o enunciado "Eu espio você", seguido por "Os brasileiros estão vulneráveis à espionagem digital - o governo, as empresas e até os cidadãos comuns". O tamanho da fonte e a cor vermelha que caracterizam a construção "Eu espio você" conferem destaque a esse enunciado quando comparado com a construção seguinte, que apresenta uma fonte de tamanho consideravelmente menor e de cor preta. Assim, podemos apontar a utilização da cor vermelha e do tamanho grande da fonte como recursos gráficos utilizados pela publicação com a possível finalidade de atrair a atenção do leitor.

Conforme assinala Fiorin (2006, p. 30), pautado no pensamento bakhtiniano, "todos os enunciados constituem-se a partir de outros". Como já apontamos, todo enunciado e todo discurso tanto se orientam para enunciados/discursos constituídos anteriormente quanto provocam o surgimento de novos enunciados/discursos. $\mathrm{O}$ enunciado "Eu espio você", presente na capa em questão, foi constituído a partir do enunciado "Eu quero você" ("I want you"), a legenda utilizada no cartaz de recrutamento para o exército norte-americano ilustrado por Flagg, reproduzido na Figura 2.

Em termos linguísticos, é possível perceber que tanto "Eu quero você" quanto "Eu espio você" apresentam, estruturalmente, um sujeito, um verbo e um complemento (objeto direto). Nessas construções, dois elementos repetem-se: nelas, temos o mesmo sujeito $(\mathrm{Eu})$ e o mesmo objeto direto (você); o único elemento linguístico diferente entre ambos é o componente verbal. No primeiro caso, temos o verbo "querer" e, no segundo, o verbo "espiar". Ambos são transitivos diretos. Esses elementos linguísticos em comum reforçam a relação dialógica existente, na dimensão verbal, entre a capa da Época e o cartaz de recrutamento norte-americano.

Convém atentar, também, para os matizes semânticos entre os verbos "querer" e "espiar". No cartaz de Flagg, o sentido do verbo "querer" é esclarecido quando atentamos para a construção "na estação mais próxima de recrutamento do Exército dos Estados Unidos". Dessa maneira, podemos afirmar que o "querer" do cartaz da Primeira Guerra Mundial associa-se ao recrutamento de sujeitos para fazer parte do exército norteamericano. Vale lembrar, ainda, que a personagem Tio Sam é o sujeito do verbo "querer", aquele que convoca os norte-americanos para fazer parte do exército. Ademais, o verbo "want", quando traduzido para a língua portuguesa, tem como equivalentes "querer",

\footnotetext{
${ }^{10}$ Conforme mencionamos, deter-nos-emos no pôster criado por James Montgomery Flagg, com o qual a capa da Época estabelece relações dialógicas. Na obra Uncle Sam wants you: World War I and the making of the modern American citizen, Capozolla (2008, p. 16) assinala que Flagg recorreu a um pôster feito por Alfred Leete, em 1914, para produzir uma capa para o jornal Leslie's Illustrated Weekly. O cartaz de Leete era composto pela imagem de Lord Kitchener, o secretário de guerra britânico, apontando para o espectador. Logo abaixo dessa figura, estavam as palavras "Your Country Needs YOU" ("Seu País Precisa de VOCE”"). Capozolla (2008, p. 16) afirma que Flagg apagou a legenda do pôster de Leete, tomou emprestada a pose de Lord Kitchener e substituiu o rosto do secretário inglês pelo seu próprio rosto, acrescentando rugas, barba e cabelo acinzentado. Estava composta a imagem do Tio Sam como a conhecemos hoje. Posteriormente, a ilustração de Flagg passou a ser utilizada em cartazes para recrutar jovens para o Exército dos Estados Unidos, com o acréscimo da legenda "I want you" ("For U.S. Army nearest recruiting station") ("Eu quero você/ na estação mais próxima de recrutamento do Exército dos Estados Unidos”).
} 
“desejar" ou mesmo "ter necessidade de". É interessante notar, portanto, que o verbo em questão possui um traço de sentido positivo.

Por seu turno, o verbo "espiar", na capa da revista Época, não parece ter esse mesmo matiz semântico positivo. O enunciado "Os brasileiros estão vulneráveis à espionagem digital - o governo, as empresas e até os cidadãos comuns" esclarece o sentido do verbo "espiar", asseverando que se trata de um processo de espionagem digital. É como se o governo norte-americano, protagonista dessa guerra digital, se sentisse na necessidade de se defender de seus alvos atuais; para isso, precisaria "estar de olho" no governo, nas empresas e nos cidadãos comuns, razão pela qual desenvolveu o sistema de espionagem mencionado. Outro aspecto relevante a ser apontado é que Obama não é o sujeito que assume ser espião, ideia essa que seria inclusive contraditória ao sigilo inerente a essa função: é a revista Época que afirma que Obama espia outras nações. Logo, diferentemente do verbo "querer", o verbo "espiar" apresenta um traço semântico negativo.

Portanto, considerando os aspectos discutidos, podemos afirmar que, no material em análise, as relações dialógicas existem em ambos os planos semióticos: no imagético, uma vez que a imagem de Obama foi constituída com base na figura do Tio Sam, e no verbal, já que o enunciado "Eu espio você", presente na capa em questão, foi constituído dialogicamente, a partir de um enunciado "já dito": o "Eu quero você" do cartaz de recrutamento ilustrado por Flagg.

A propriedade da refração de sentido também está presente em "Eu espio você", já que a Época constrói, através de diferentes meios semióticos, sua interpretação, sua visão de mundo particular em relação ao então presidente dos Estados Unidos e em relação ao sistema de espionagem digital da inteligência norte-americana. Podemos apontar que a revista dá contornos semânticos negativos a Barack Obama e à espionagem digital estadunidense quanto caracteriza, visualmente, o presidente com ares de inflexibilidade, significando-o como o comandante, em certa medida, ameaçador dessa guerra eletrônica, e também como um espião norte-americano. Isso também pode ser verificado no plano semiótico verbal, quando a Época, ao dar sentido à vigilância eletrônica, refere-se à situação de vulnerabilidade daqueles que estão sendo espiados pelos Estados Unidos, colocando, de certa forma, o referido país numa posição de controle, por monitorar as informações eletrônicas de outras nações.

Além do mais, levando em conta as observações apresentadas até então, julgamos pertinente enfatizar a natureza ideológica dos signos verbais e visuais componentes da capa da revista analisada, por meio de sua dimensão dialógica.

No que se refere aos aspectos imagéticos, destacamos a associação entre a figura de Tio Sam e a imagem de Obama como uma escolha que manifesta posições ideológicas, já que, ao fazer essa relação, a Época intenta aproximar a postura política das duas figuras diante dos confrontos em que ambas se envolveram: a Primeira Guerra Mundial e uma guerra digital, respectivamente. Essa aproximação evoca o papel de liderança do Tio Sam no que tange ao recrutamento de jovens militares para o exército dos Estados Unidos, bem como a função de líder de Obama nesse confronto eletrônico. Assim, através dos aspectos visuais, a Época recupera dialogicamente a personagem ilustrada por Flagg, o papel assumido por Tio Sam no recrutamento para o exército estadunidense e o próprio período 
histórico da Primeira Guerra Mundial. Dessa maneira, através da associação entre as duas figuras, a Época, como explicamos, atribui esse mesmo papel de líder a Obama, agora em relação a um conflito que se dá em âmbito virtual. Os elementos visuais, assim como os verbais, que compõem a referida capa encontram-se, dessa forma, revestidos ideologicamente. A revista, então, atribui valor negativo a Obama e ao processo de espionagem digital, mostrando, em suma, sua reprovação frente ao assunto que aborda.

É igualmente pertinente observar que, no cartaz de Flagg, Tio Sam dirige-se aos jovens militares, para recrutá-los para o exército dos Estados Unidos. Já na capa da Época, Obama aponta para o leitor da publicação, isto é, para o "cidadão comum" mencionado verbalmente no enunciado da capa, mais especificamente, o cidadão brasileiro, que, assim como o governo e as empresas, estaria vulnerável e seria o alvo da espionagem digital realizada pela inteligência norte-americana. A concepção de Obama como o líder de um país envolvido em uma guerra digital, possibilitada pela vigilância eletrônica, é reiterada, também, no plano semiótico verbal.

Aliás, faz-se importante indicar que a capa da revista como um todo parece simular o cartaz de recrutamento para o exército norte-americano. No cartaz de Flagg, temos, estruturalmente, uma figura masculina (Tio Sam) com sua indumentária característica, bem como uma parte do enunciado escrita com recursos gráficos de ênfase - cor e tamanho da fonte utilizada; essa parte do enunciado é acompanhada por outra, que lhe serve como explicação e não possui os mesmos recursos gráficos usados para atrair a atenção do leitor.

A capa da edição 790 da revista Época apresenta, também, uma figura masculina (Obama), trajando as vestimentas típicas de Tio Sam, além de um enunciado grafado com uma fonte de cor e de tamanho mais chamativos, seguido por outro enunciado que funciona para esclarecê-lo. Este, por sua vez, é escrito numa fonte de tamanho menor e com cor menos chamativa. Desse modo, é possível dizer que a capa da revista "espelha" o cartaz de Flagg, motivo pelo qual podemos apontar uma relação dialógica entre os gêneros do discurso cartaz e capa de revista.

Além disso, podemos afirmar que a interpretação da Época não é um consenso em relação ao sistema de espionagem norte-americano e à postura de Obama, sendo uma refração (interpretação) possível sobre a vigilância eletrônica dos Estados Unidos, em meio a diversas outras refrações sobre essa questão.

No que concerne às relações estabelecidas entre os referidos planos semióticos, podemos perceber que, para construir sentidos acerca da vigilância eletrônica, os signos ideológicos verbais "apoiam-se" nos signos ideológicos visuais e vice-versa. No plano verbal, a Época defende que os Estados Unidos, materializados na figura de Obama, estão espiando os cidadãos comuns. A caricatura de Obama e a indumentária característica do Tio Sam consistem em signos ideológicos visuais que funcionam a serviço dos elementos verbais, representando o então presidente como líder de um país inserido, agora, numa guerra digital. Desse modo, os elementos visuais corroboram com as afirmações realizadas no nível verbal e vice-versa. Portanto, os planos semióticos apoiam-se mutuamente para manifestar a posição da revista Época no que se refere à espionagem digital realizada pela inteligência estadunidense. 


\section{Conclusão}

Bakhtin/Volochínov (2012) fazem considerações específicas em relação à função ideológica dos signos verbais, defendendo a ideia de que as palavras "tecidas por uma multidão de fios ideológicos" (BAKHTIN/VOLOCHÍNOV, 2012, p. 42). No entanto, os pensadores do Círculo de Bakhtin, em suas obras, não negligenciam, de modo algum, as outras dimensões da linguagem, reconhecendo que signos não verbais também podem ser revestidos ideológica e, por consequência, axiologicamente. Dessa forma, como buscamos evidenciar no presente artigo, essa postura teórica atenta para o fato de que a ideologia pode ganhar materialidade em diferentes semioses.

Com nosso estudo, pudemos perceber que, na composição discursiva da capa da edição 790, a revista Época recorreu a elementos verbais e a elementos visuais para construir, dialógica e ideologicamente, a imagem do presidente norte-americano Barack Obama e para posicionar-se axiologicamente em relação ao sistema de espionagem digital desenvolvido pela inteligência dos Estados Unidos. Convém ressaltar ainda que buscamos dar a devida atenção às dimensões linguísticas verbal e visual em razão da natureza multissemiótica de nosso objeto de análise. A capa da edição 790 da Época pode ser entendida como um tex to verbo-visual, de forma que os sentidos e os efeitos de sentido desse material são constituídos na interação entre os aspectos verbais e visuais. Assim, não poderíamos deixar de atentar para as duas modalidades linguísticas que constituem o material analisado.

Considerando os apontamentos que fizemos acerca das materialidades sígnicas verbal e visual, pudemos perceber que aproximação de Obama e da guerra digital com Tio Sam e com a Primeira Guerra Mundial se dá através da associação entre dois planos semióticos, o verbal e o imagético, isto é, através do enunciado "Eu espio você" e da composição visual da figura central da capa da revista em foco. Ao estabelecer relações entre essas duas figuras estadunidenses e entre as situações bélicas em que elas se envolvem, pudemos observar que a Época fez escolhas, inevitavelmente, ideológicas: a ligação entre o então presidente Barack Obama e a personagem Tio Sam e entre os momentos históricos em que ambos estão inseridos permitem-nos dizer, conforme já indicamos, que a Época considera a espionagem digital, bem como os computadores e a internet, como armas utilizadas pelo governo norte-americano, reforçando a ideia da existência de uma guerra digital. Nessa linha de pensamento, o "I want you" da propaganda de guerra daria lugar, na contemporaneidade, ao "I watch you", no sentido de observar, de vigiar, em referência à vigilância eletrônica e, mais especificamente, ao sistema de espionagem digital norte-americano.

Por fim, consideramos importante enfatizar a pertinência da utilização da teoria dialógica do discurso como ferramenta teórica no estudo do material multissemiótico em questão. Acreditamos, ainda, que a argumentação desenvolvida no artigo servirá para dar continuidade às reflexões já existentes a respeito de como materiais compostos por diferentes semioses podem ser analisados com base nessa proposta de estudo. 


\section{Referências bibliográficas}

ACOSTA-PEREIRA, R.; RODRIGUES, R.H. Os gêneros do discurso sob perspectiva da Análise Dialógica do Discurso. LETRAS, Santa Maria, v. 20, n. 40, p. 147-162, 2010.

AGUILHAR, Ligia. Precisamos de uma primavera cibernética. Disponível em <http://blogs.estadao.com.br/link/precisamos-de-uma-primavera-cibernetica/>; acesso em jun. 2016.

BAKHTIN, M. Questões de literatura e de estética: a teoria do romance. Trad. Bras. São Paulo: Hucitec, 2014.

- [VOLOCHÍNOV, V.]. Marxismo e filosofia da linguagem: problemas fundamentais do método sociológico na ciência da linguagem. São Paulo: Hucitec, 2012.

Estética da criação verbal. $6^{\text {a }}$. ed. Trad. Bras. São Paulo: Martins Fontes, 2011.

Problemas da poética de Dostoievski. $5^{\mathrm{a}}$. ed. Trad. Bras. Rio de Janeiro: Forense Universitária, 2010.

; VOLOCHÍNOV, V. Discourse in life and discourse in art: concerning sociological poetics. Em: VOLOCHÍNOV, V. Freudism. New York: Academic Press, 1976. [Trad. de Carlos Alberto Faraco e Cristovão Tezza para uso didático.]

BRAIT, B. Olhar e ler: verbo-visualidade em perspectiva dialógica. BAKHTINIANA [Revista de Estudos Discursivos], São Paulo, v. 8, n. 2, p. 43-66, jul./dez. 2013.

Análise e teoria do discurso. Em: BRAIT, B. (Org.) Bakhtin: outros conceitoschave. São Paulo: Contexto, 2010a. p. 9-31.

Tramas verbo-visuais da linguagem. In: BRAIT, B. (Org.) Literatura e outras linguagens. São Paulo: Contexto, 2010b. p. 193-228.

CAPOZOLLA, C. Uncle Sam wants you: World War I and the making of the modern American citizen. Nova York: Oxford University Press, 2008.

CASTRO, Gilberto de. O marxismo e a ideologia em Bakhtin. Em: DE PAULA, L.; STAFUZZA, G. (Orgs.). Círculo de Bakhtin: teoria inclassificável. Campinas, SP: Mercado de Letras, 2010. p. 175-202.

FARACO, C.A. Criação ideológica e dialogismo. Em: Linguagem \& diálogo: as ideias linguísticas do Círculo de Bakhtin. Curitiba: Criar Edições, 2009. p. 45-97.

FIORIN, J.L. Interdiscursividade e intertextualidade. Em: BRAIT, B. (Org.) Bakhtin: outros conceitos-chave. São Paulo: Contexto, 2010. p. 161-193.

O dialogismo. Em: Introdução ao pensamento de Bakhtin. São Paulo: Ática, 2006. p. 18-59. 
LAKATOS, E.M.; MARCONI, M. de A. Fundamentos de metodologia científica. $5^{\text {a }}$. ed. São Paulo: Atlas, 2003.

MIOTELLO, V. Ideologia. Em: BRAIT, B. (Org.) Bakhtin: conceitos-chave. São Paulo: Contexto, 2012. p. 167-176.

PONZIO, A. Signo e ideologia. Em: A Revolução Bakhtiniana: o pensamento de Bakhtin e a ideologia contemporânea. São Paulo: Contexto, 2012. p. 109-159.

REVISTA ÉPOCA. Eu espio você - Os brasileiros estão vulneráveis à espionagem digital - o governo, as empresas e até os cidadãos comuns. [Capa]. Edição 790. Disponível em: $<$ http://contentviewer.adobe.com/s/Revista\%20\%C3\%89poca/3297fac0e14742989cfd8a d8393d9e96/Revista\%20\%C3\%89poca\%20790/001_Capa.html>; acesso em jun. 2016.

SILVA, R.S. Desenhando uma nova ordem mundial: o poder dos Estados Unidos e as suas representações caricaturais no início do século XX. MÉTIS: história \& cultura, Caxias do Sul, v. 5, n. 9, p. 117-144, jan./jun. 2006.

STAM, R. Bakhtin e a crítica midiática. Em: GOULART, A.P; SACRAMENTO, I. (Orgs.) Mikhail Bakhtin: linguagem, cultura e mídia. São Carlos: Pedro \& João Editores, 2010. pp. 331-357.

Artigo recebido em: junho de 2016.

Aprovado e revisado em: julho de 2016.

Publicado em: agosto de 2016

\section{Para citar este texto:}

SILVA, Elayne Gonçalves; GONÇALVES, João Batista Costa. “'I watch you': uma análise dialógica da linguagem verbo-visual de capa da revista Época sobre a espionagem digital do governo norte-americano. Entremeios [Revista de Estudos do Discurso], Seção Temática [Os discursos sobre segurança em meio a políticas e processos de significação], Programa de Pós-graduação em Ciências da Linguagem (PPGCL), Universidade do Vale do Sapucaí, Pouso Alegre (MG), vol. 13, p. 213-229, jul. - dez. 2016.

DOI: http://dx.doi.org/10.20337/ISSN2179-3514revistaENTREMEIOSvol13pagina213a229 